\title{
The erector spinae plane block: a narrative review
}

\author{
Pablo Kot ${ }^{1}$, Pablo Rodriguez ${ }^{1}$, Manuel Granell ${ }^{1}$, Beatriz Cano ${ }^{2}$, \\ Lucas Rovira ${ }^{1}$, Javier Morales ${ }^{1}$, Ana Broseta ${ }^{1}$, and Jose De Andrés ${ }^{1}$ \\ ${ }^{1}$ Department of Anesthesia, Critical Care and Pain Medicine, University General Hospital Consortium of Valencia, \\ ${ }^{2}$ Department of Hospital Nursing, University General Hospital Consortium of Valencia, Valencia, Spain
}

Regional anesthesia and pain management have experienced advances in recent years, especially with the advent of fascial plane blocks. The erector spinae plane block is one of the newest techniques to be described. In the past two years, publications referring to ESP block have increased significantly. The objective of this review is to analyze the articles about ESP block that have been published to date. We performed a search in the main databases and identified 368 articles. After a selection of the relevant articles, 125 studies were found eligible and were included in the review. The ESP block is performed by depositing the local anesthetic in the fascial plane, deeper than the erector spinae muscle at the tip of the transverse process of the vertebra. Many cases of its use have been described with satisfactory results in the treatment of both acute pain and chronic pain. The applicability of the technique covers many clinical scenarios. Of the 98 case reports reviewed, 12 and 87 articles, respectively described the technique as a treatment for chronic pain and acute pain. The single-shot was the most frequently used technique. As described in the articles published to date, the technique is easy to perform and has a low rate of complications. However, despite the effectiveness of the technique, further studies are necessary to obtain more evidence of its actions.

Keywords: Erector spinae plane block; ESP block; Fascial plane block; Pain; Regional anesthesia.

\section{Introduction}

Fascial plane blocks are techniques used to manage pain, both in the perioperative period and in the treatment of chron-

Corresponding author: Pablo Kot, M.D.

Department of Anesthesia, Critical Care and Pain Medicine, University General Hospital Consortium of Valencia, Av Tres Cruces,

2, Valencia 46014, Spain

Tel: 34-963-131-800, Fax: 34-963-131-975

Email: pablo_kot@hotmail.com

ORCID: https://orcid.org/0000-0001-9322-6348

This article includes supplementary video clips.

Received: January 10, 2019.

Revised: March 6, 2019.

Accepted: March 13, 2019.

Korean J Anesthesiol 2019 June 72(3): 209-220

https://doi.org/10.4097/kja.d.19.00012 ic pain. In recent years, different types of fascial blocks have been described and there has been an increase in their clinical applications. The main advantages offered by these techniques include the ease of performing them, the analgesic efficacy, and the low risk of complications. One of the newest techniques that have been described recently is the erector spinae plane (ESP) block. It was first described by Forero et al. [1] in 2016 for the treatment of chronic thoracic neuropathic pain and postoperative pain in thoracic surgery. Since then, many articles have been published describing the application of the technique for a wide variety of clinical scenarios. The objective of this review is to analyze the articles about ESP block that have been published to date. Through the study of these articles, we intend to describe its procedural technique, indications, effectiveness, and possible complications in the different scenarios reported.

\section{Anatomy}

The erector spinae muscle (ESM) is a complex formed by the

(c) This is an open-access article distributed under the terms of the Creative Commons Attribution Non-Commercial License (http://creativecommons.org/ licenses/by-nc/4.0/), which permits unrestricted non-commercial use, distribution, and reproduction in any medium, provided the original work is properly cited. 
spinalis, longissimus thoracis, and iliocostalis muscles that run vertically in the back (Fig. 1). The ESP block is performed by depositing the local anesthetic (LA) in the fascial plane, deeper than the ESM at the tip of the transverse process of the vertebra. Hence, LA is distributed in the cranio-caudal fascial plane one dermatome a median of each $3.4 \mathrm{ml}$ of injected volume [2]. Additionally, it diffuses anteriorly to the paravertebral and epidural spaces, and laterally to the intercostal space at several levels [3-5]. The LA exerts its effect on the ventral and dorsal ramus of the spinal nerve. The ventral ramus (intercostal nerve) is divided into the anterior and lateral branches. Its terminal branches provide the sensory innervation of the entire anterolateral wall. The dorsal ramus is divided into 2 terminal branches and it gives the sensory innervation to the posterior wall. Furthermore, the diffusion of LA to the paravertebral space through the costotransverse foramina and the intertransverse complex (intertransverse and costotransverse ligaments: levators, rotators, and intercostal muscles) provides both visceral and somatic analgesia. This diffusion into the epidural space and the neural foramina has been reported in anatomical studies that examined 2 to 5 vertebral levels that were centered near the injection site. However, this diffusion was not observed consistently in all cadaver studies.

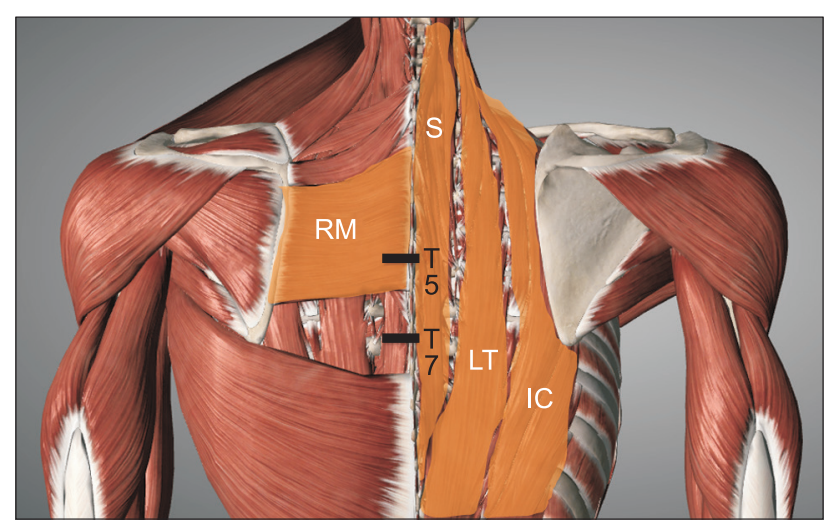

Fig. 1. Anatomy of the erector spinae muscle. RM: Rhomboid major muscle; Erector spinae muscle (spinalis [S], longissimus thoracis [LT], and iliocostalis [IC]), T7: Thoracic vertebral 7, T5: Thoracic vertebral 5.

\section{Technique}

The position of the patient for the realization of the block includes: sitting, lying on the side, or lying prone. The technique can be performed with the patient awake or under the effects of general anesthesia. In pediatric patients, it is advisable to perform the procedure after the induction of anesthesia. However, there is no consensus about the best method for adult patients. The awake technique provides the advantage of being able to assess the efficacy and level of analgesia by means of a skin sensitivity test. However, the poor correlation between analgesia and skin sensitivity has been reported [6].

Although cases of blind puncture or under fluoroscopy have been described [7], the technique is usually guided by ultrasound. Usually, a high-frequency linear ultrasound transducer is used to block the thoracic level, and a convex transducer is used to block the lumbar level. The probe is placed in a transverse orientation to identify the spinous process. Once the level is identified, the probe is moved $3 \mathrm{~cm}$ laterally until the transverse process is identified. The probe should be rotated 90 degrees on the transverse process by placing it in a parasagittal plane. Three muscles must be identified as superficial to the hyperechoic transverse process shadow, and they include the trapezius, rhomboid major, and erector spinae (Fig. 2). These three muscles are visualized at the level of the fifth thoracic vertebra (standard level for a thoracic block); however, the rhomboid major muscle disappears at the level of the seventh thoracic vertebra (in lower blocks). The needle is inserted in the plane. The procedure can be performed in the cranio-caudal or opposite direction depending on the conditions and the region to be treated. Moreover, the block can be administered by a single shot or with a catheter insertion for continuous infusion; with the target as the transverse process. A hydrodissection should also be carried out with saline solution, and the local anesthetic must be deposited in the fascial plane, deeper than ESM at the tip of the transverse process of the vertebra (Fig. 3).
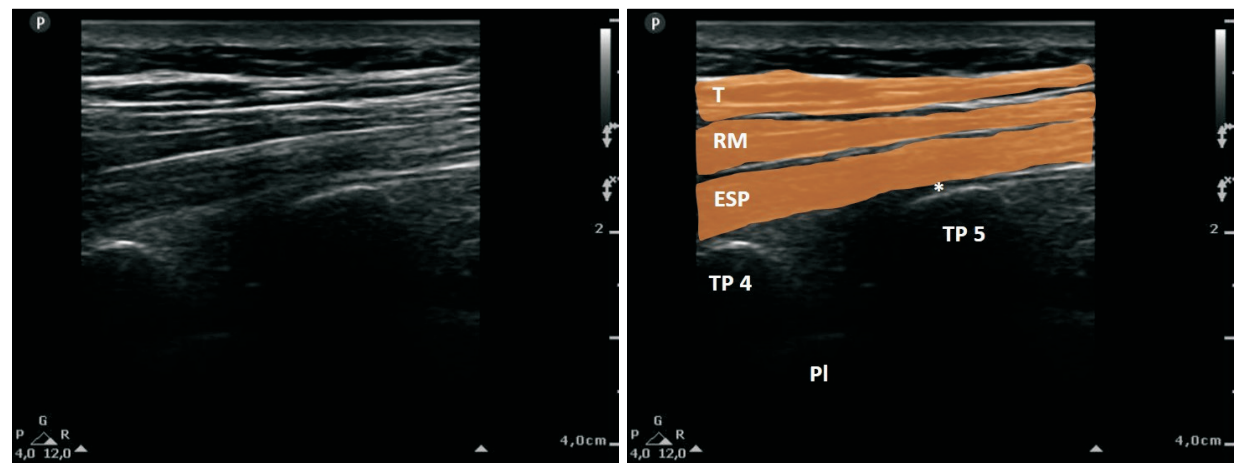

Fig. 2. Sonoanatomy of the ESP block at T5 level. TP: transverse process, T: trapezius, RM: Rhomboid major, ESP: erector spinae, Pl: Pleura. *Needle tip place. 


\section{Materials and Methods}

This is a narrative review. We performed a literature search for articles related to the ESP block in Medline, PubMed, Cochrane Library, and Google Scholar. The search period was from January 1, 2016, to December 1, 2018. The inclusion criteria were the articles related to ESP block that were identified in the search; these articles included letters to the editor, commentaries, case reports, case series, cadaver studies, observational studies, reviews, and clinical trials in adult and pediatric patients. The exclusion criteria included non-English language articles, duplicates articles, animal studies, irrelevant articles or articles that were not related to the ESP block. The search terms used included: "Erector Spinae Plane Block," "ESP block," and "Erector Spinae block."

Initially, we identified 368 articles, out of which 233 articles were excluded because they were duplicates; however, 4 additional articles were identified from a different source and included in the review. Of the 139 remaining articles, 2 were excluded after reading the abstracts [126,127] which revealed that they were not related to ESP blocks. One was a review of adjuvant nerve blocks, and the other was an anatomical study of a different type of block. We eventually completed the reading of 137 articles, out of which 12 were excluded [128-139] for their irrelevance for this review. Finally, 125 studies were included in this review (Fig. 4). The data extracted in the case reports includes the following: type of pain and painful region, intervention performed, number of subjects treated, level of realization of blockage, use of catheter or single shot, unilateral or bilateral, local anesthetic used, average numerical rating scale (NRS) for pain, and presence of complications and other relevant observations. The average NRS included in the table was calculated by calculating the mean of the first NRS value reported in each case (in the cases where the pain was described in the first 12 hours post-block). The most relevant findings from clinical trials and observational studies are described in the results.
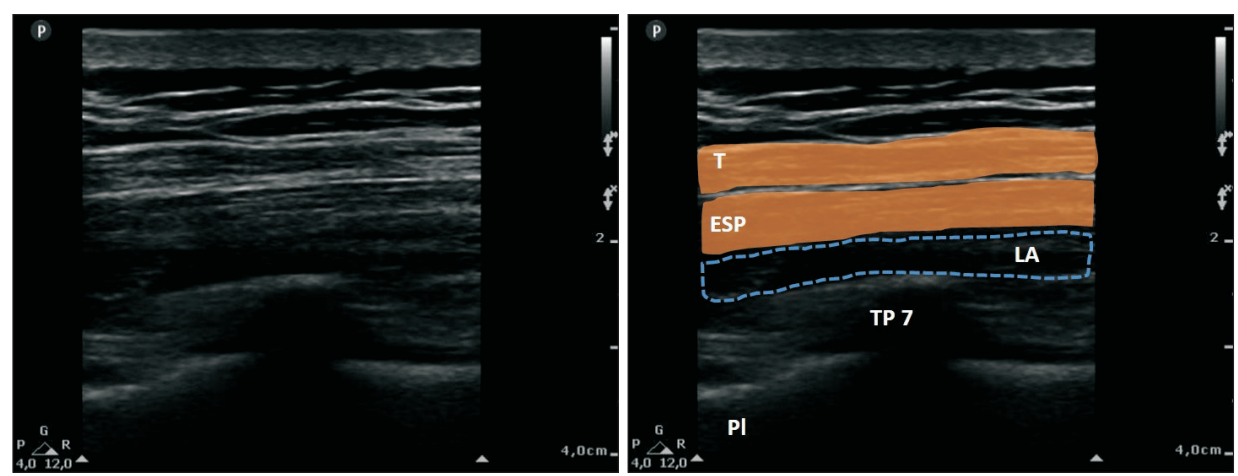

Fig. 3. Sonoanatomy of ESP block at T7 level with LA diffusion shown in the dashed area. T: trepezius, ESP: erector spinae, LA: local anesthetic, TP: transverse process, $\mathrm{Pl}$ : pleura.

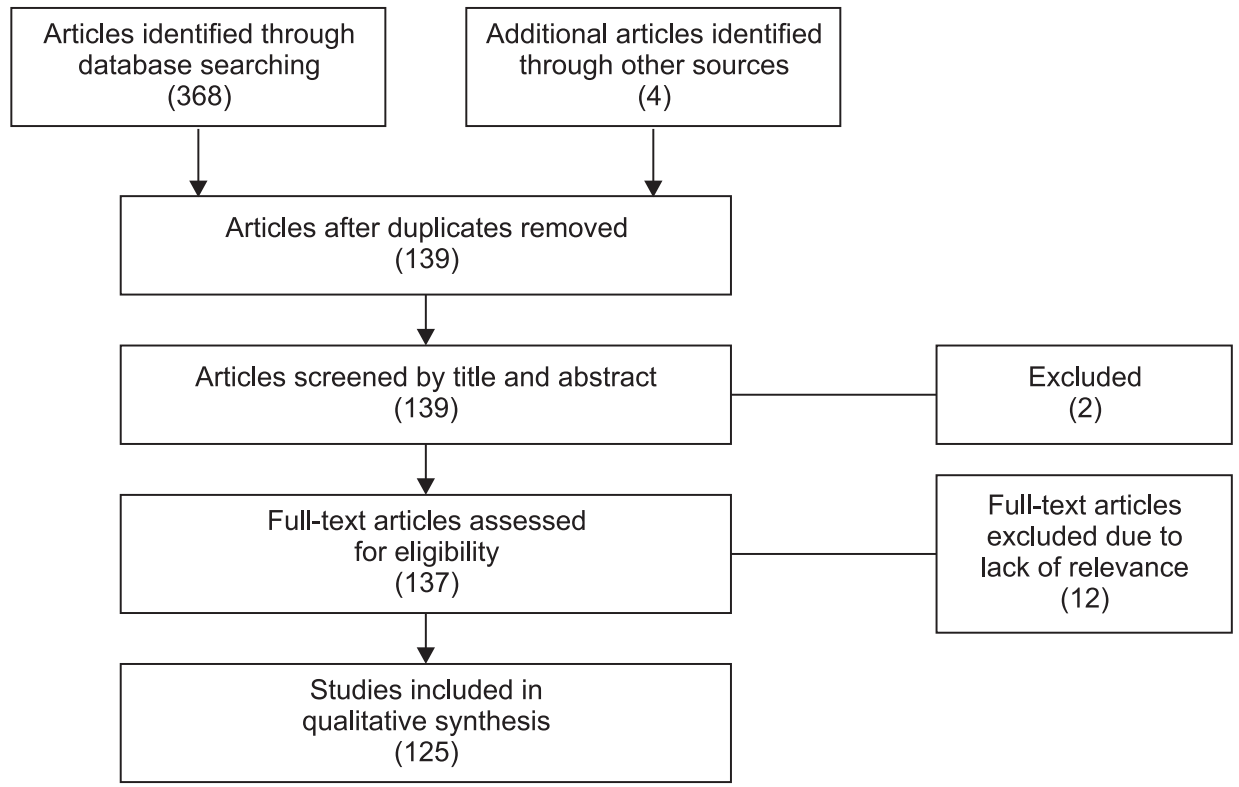

Fig. 4. Algorithm of the different phases of articles inclusion criteria in the review. 


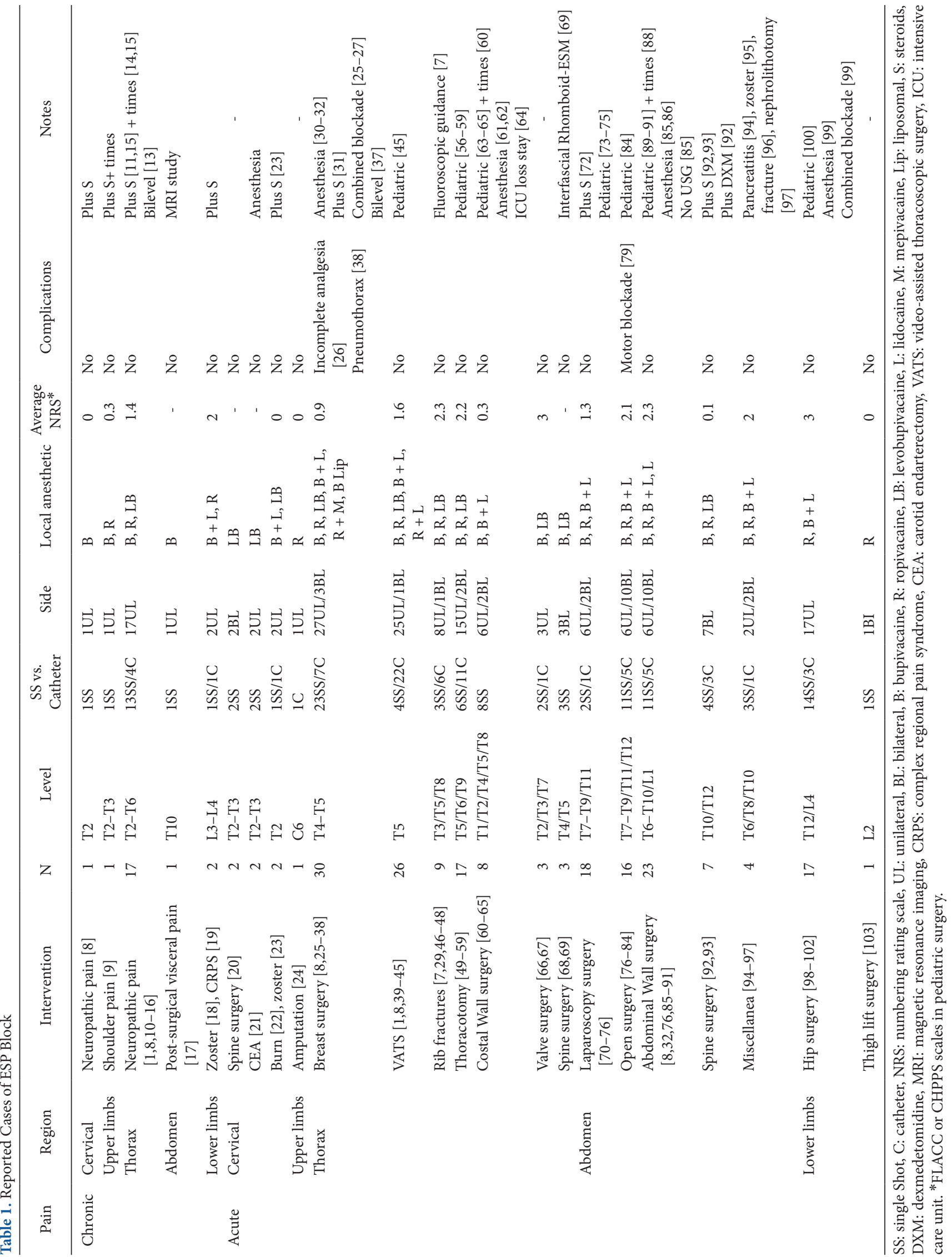




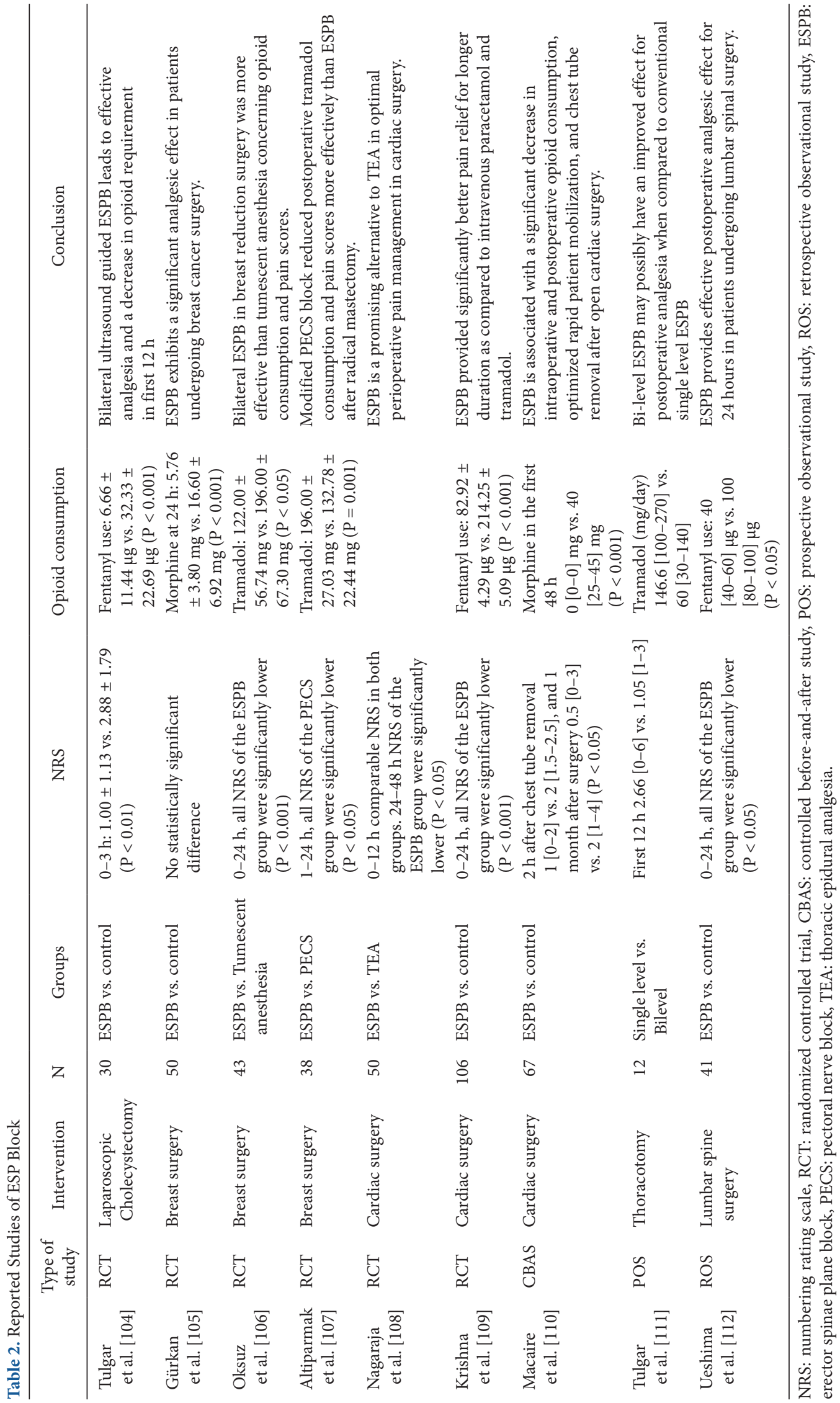




\section{Results}

The 125 articles finally included in this review included: 6 randomized controlled trials [104-109], 1 consecutive controlled before-and-after study [110], 2 observational studies [111,112], 3 review articles [2,113,121], 5 anatomical studies [3-5,124,125], 98 case reports [1,7-103], and 10 opinion articles $[6,114-120,122-126]$. The case reports are described in Table 1 [1,7-103]. All case reports included a total of 211 patients in 98 articles. Of these case reports, 12 and 87 articles respectively described the technique as a treatment for chronic pain and acute pain. However, both scenarios described cases where the block was utilized for therapy at the cervical level, upper limbs, thoracic level, abdominal level, and lower limbs. The single-shot technique was most frequently used, while the most commonly used local anesthetics were bupivacaine and ropivacaine. The mean NRS for analgesia measurement reported in all cases was $\leq 3$, and the only complications described were incomplete analgesia, pneumothorax, and motor blockade.

Only six prospective trials were identified in this review. Tulgar et al. [104] evaluated the ESP block for postoperative analgesia in laparoscopic cholecystectomy. They compared 30 patients in two groups (ESP group and a control group). Their results included consumption of tramadol, as well as a score on the NRS scale lower in the ESP group during the first $3 \mathrm{~h}$. Gürkan et al. [105] evaluated the ESP block for postoperative analgesia in breast surgery. They compared 50 patients in two groups (ESP group and control group). Total morphine consumption in block group decreased by $65 \%$ at $24 \mathrm{~h}$ compared to the control group $(5.76 \pm 3.80 \mathrm{mg}$ vs. $16.60 \pm 6.92 \mathrm{mg})$, but there was no statistically significant difference between the groups in terms of NRS scores. Oksuz et al. [106] also compared the bilateral ESP block with tumescent anesthesia for postoperative analgesia in 43 patients undergoing reduction mammoplasty. The NRS scores and the requirement for additional analgesia were statistically significantly lower in the ESP group. Altiparmak et al. [107] compared the effects of modified pectoral nerve (PECS) block and ESP block after radical mastectomy surgery. They concluded that PECS block reduced postoperative tramadol consumption (132.78 $\pm 22.44 \mathrm{mg}$ vs. $196.00 \pm 27.03 \mathrm{mg})$ and NRS scores after the postoperative $1 \mathrm{~h}, 2 \mathrm{~h}, 12 \mathrm{~h}$, and $24 \mathrm{~h}$ more effectively than the ESP block. Nagaraja et al. [108] compared the continuous thoracic epidural with bilateral ESP block in cardiac surgery among 50 patients. The NRS scores were statistically significantly lower in the ESP group at $24 \mathrm{~h}, 36 \mathrm{~h}$, and 48 h. Incentive spirometry, ventilator, and intensive care unit duration were comparable between the groups. Krishna et al. [109] evaluated the ESP block for postoperative analgesia in cardiac surgery. They compared 106 patients in two groups (ESP group and control group) and concluded that ESP block provided sig- nificantly better pain relief at rest (NRS were significantly lesser at all measured time points) and for a longer duration than the control group ( $8.98 \pm 0.14$ hours vs. $4.60 \pm 0.12$ hours).

One consecutive, patient-matched, controlled before-and-after study was included in this review. Macaire et al. [110] compared 67 patients undergoing cardiac surgery in 2 groups: a historical group of 20 patients who received intravenous morphine $(0.5 \mathrm{mg} / \mathrm{h})$ and nefopam $(100 \mathrm{mg} / 24 \mathrm{~h})$ with a group of 47 patients who received continuous bilateral ESP block. The ESP group was associated with less pain and lower opioid consumption (40 [25-45] $\mathrm{mg}$ in the control group vs. 0 [0-0] mg in the ESP group $[\mathrm{P}<0.001])$. In addition, the mobilization of the patients and the removal of the thoracic tube was performed earlier in the ESP group.

Two observational studies were identified in this review. Tulgar et al. [111] reported their results of comparing the single or bi-level application of ESP block in 12 patients undergoing thoracotomy. They observed that the NRS scores in the first 12 $\mathrm{h}$ were higher in the single level group than in the bi-level group. While the average fentanyl use in patients in the single level group was $37.5 \mathrm{mg}$ in the first postoperative hour, no patient in the bi-level group required fentanyl. Additionally, tramadol use was lesser in patients undergoing bi-level ESP block. Ueshima et al. [112] compared 41 patients undergoing lumbar spinal surgery in a retrospective study. They observed that the NRS scores and the amount of fentanyl administered were lower in the ESP block group than in the control group at all measured time points, with no significant difference in the incidence of complications between the two groups. The 9 studies described are summarized in Table 2.

\section{Discussion}

Regional anesthesia and pain management have experienced advances in recent years with the advent of fascial plane blockages. One of the newest techniques described in the literature has been the ESP block. In the past two years, the publications referring to ESP block have increased significantly [113,114].

Furthermore, most published articles are case reports; hence, from the study of these reports, it can be concluded that the ESP block is an effective analgesic technique in a variety of clinical scenarios. It can be utilized successfully in the treatment of acute and chronic pain. Likewise, it has also been effective for analgesia at the cervical, thoracic, and abdominal levels. Likewise, studies indicate that it can provide adequate analgesia in the upper or lower limbs if it is performed at the high thoracic and lumbar levels, respectively. The procedure has mostly been described for postoperative analgesia at the thoracic level. Additionally, it has a low rate of reported complications. However, given the majority of case reports reported in this review, the ev- 
idence of the description is low and there is a risk of publication bias (since it is possible that the studies with unsuccessful blockade were not published). Another limitation of our review is the lack of prospective studies. Prospective randomized controlled trials that compared the technique with a control group revealed that the ESP technique reduces both the pain scale score and the need for additional analgesia. However, other studies that compared the ESP block with another technique were not unanimous in their favor of it. The difference in analgesic effectiveness, which differs according to the scenario and comparative technique, means that more prospective studies are needed to help improve the evidence of its use.

Most authors affirm that ESP block is a technique that has great advantages over conventional techniques performed close to the neuroaxis. First, it is an easy technique to perform as the visualization of the target by ultrasound is very simple and it is not difficult to direct the needle towards it. Second, the technique has a low risk of complications. Important structures (such as main vessels, pleura, or medulla) whose injury can cause serious complications, are far from the target of blockage. Although several authors have postulated that the ESP block is the same technique as the retrolaminar block $[117,118]$ or an "accidental paravertebral block" $[119,120]$, both clinical and anatomical studies (in vivo and cadaveric) seem to indicate that it is a different technique $[3,121,124,125]$. Moreover, it is performed differently, the objective is different in all cases and the diffusion of LA differs between them.

Given that this procedure is easy to perform and is relatively safe, several authors have expressed the opinion that it could be part of the multimodal analgesia of the enhanced recovery after surgery programs [110]. Additionally, catheter insertion has been described as an easy procedure to perform; hence, the possibility of performing the technique for prolonged analgesia is available. However, being such a novel blockade technique, the lack of more well-designed prospective studies makes recommending its use in these programs has not yet occurred.

Therefore, we can conclude that ESP block seems to be an effective analgesic technique at many levels. This offers us the opportunity to utilize it in many clinical situations. Although it is not the technique of first choice in most situations, it is a suitable alternative, especially in scenarios in which the technique of first choice constitutes an important risk or is directly contraindicated. Moreover, ESP block has been described as an effective alternative when paravertebral or epidural block are contraindicated due to rejection by the patient $[33,45,56,83]$, thrombocytopenia $[39,41]$, antiplatelet [52] or anticoagulant treatments [53], or coagulopathy [58]. Other authors have shown its effectiveness as a second line therapy after the unsuccessful insertion of an epidural catheter [41] or its failure [49,51]. Additionally, it has been reported to successfully induce anesthesia in patients with a high risk of adverse effects from general anesthesia [30,31,85,86,99]. However, more randomized controlled trials are necessary to establish the best indications of ESP block as an analgesic technique, in chronic, acute, and postoperative pain.

\section{Conflicts of Interest}

No potential conflict of interest relevant to this article was reported.

\section{Author Contributions}

Pablo Kot (Conceptualization; Data curation; Validation; Visualization; Writing - original draft; Writing - review \& editing) Pablo Rodriguez (Conceptualization; Supervision; Validation) Manuel Granell (Conceptualization; Supervision; Validation; Visualization)

Beatriz Cano (Conceptualization)

Lucas Rovira (Data curation; Supervision; Validation; Visualization) Javier Morales (Conceptualization)

Ana Broseta (Conceptualization)

Jose De Andrés (Supervision; Validation; Visualization)

\section{ORCID}

Pablo Kot, https://orcid.org/0000-0001-9322-6348

Pablo Rodriguez, https://orcid.org/0000-0002-7487-0098

Manuel Granell, https://orcid.org/0000-0002-8350-3871

Beatriz Cano, https://orcid.org/0000-0002-6515-4743

Lucas Rovira, https://orcid.org/0000-0002-3775-8144

Javier Morales, https://orcid.org/0000-0002-6744-121X

Ana Broseta, https://orcid.org/0000-0001-7586-0513

Jose De Andrés, https://orcid.org/0000-0002-5789-5752

\section{Supplementary Materials}

Futher details are presented in the online version of this article (Available from https://doi.org/10.4097/kja.d.19.00012).

\section{References}

1. Forero M, Adhikary SD, Lopez H, Tsui C, Chin KJ. The erector spinae plane block: a novel analgesic technique in thoracic neuropathic pain. Reg Anesth Pain Med 2016; 41: 621-7. 
2. De Cassai A, Tonetti T. Local anesthetic spread during erector spinae plane block. J Clin Anesth 2018; 48: 60-1.

3. Adhikary SD, Bernard S, Lopez H, Chin KJ. Erector spinae plane block versus retrolaminar block: a magnetic resonance imaging and anatomical study. Reg Anesth Pain Med 2018; 43: 756-62.

4. Ueshima H, Hiroshi O. Spread of local anesthetic solution in the erector spinae plane block. J Clin Anesth 2018; 45: 23.

5. Vidal E, Giménez H, Forero M, Fajardo M. Erector spinae plane block: a cadaver study to determine its mechanism of action. Rev Esp Anestesiol Reanim 2018; 65: 514-9.

6. Muñoz-Leyva F, Mendiola WE, Bonilla AJ, Cubillos J, Moreno DA, Chin KJ. In reply to "Continuous erector spinae plane (ESP) block: optimizing the analgesia technique". J Cardiothorac Vasc Anesth 2018; 32: e3-4.

7. Jadon A, Swarupa CP, Amir M. Fluoroscopic-guided erector spinae plane block: a feasible option. Indian J Anaesth 2018; 62: 806-8.

8. Jain K, Jaiswal V, Puri A. Erector spinae plane block: Relatively new block on horizon with a wide spectrum of application - A case series. Indian J Anaesth 2018; 62: 809-13.

9. Forero M, Rajarathinam M, Adhikary SD, Chin KJ. Erector spinae plane block for the management of chronic shoulder pain: a case report. Can J Anaesth 2018; 65: 288-93.

10. Aydin T, Balaban O, Acar A. Ultrasound guided continuous erector spinae plane block for pain management in pulmonary malignancy. J Clin Anesth 2018; 46: 63-4.

11. Fusco P, DI Carlo S, Scimia P, Luciani A, Petrucci E, Marinangeli F. Could the new ultrasound-guided erector spinae plane block be a valid alternative to paravertebral block in chronic chest pain syndromes? Minerva Anestesiol 2017; 83: 1112-3.

12. Ueshima H, Otake H. Erector spinae plane block for pain management of wide post-herpetic neuralgia. J Clin Anesth 2018; 51: 37.

13. Balaban O, Aydın T. Ultrasound guided bi-level erector spinae plane block for pain management in Herpes Zoster. J Clin Anesth 2019; 52: 31-2.

14. Ahiskalioglu A, Alici HA, Ciftci B, Celik M, Karaca O. Continuous ultrasound guided erector spinae plane block for the management of chronic pain. Anaesth Crit Care Pain Med 2017. Advance Access published on Dec 15, 2017. doi: 10.1016/j.accpm.2017.11.014.

15. Forero M, Rajarathinam M, Adhikary S, Chin KJ. Erector spinae plane (ESP) block in the management of post thoracotomy pain syndrome: a case series. Scand J Pain 2017; 17: 325-9.

16. Ramos J, Peng P, Forero M. Long-term continuous erector spinae plane block for palliative pain control in a patient with pleural mesothelioma. Can J Anaesth 2018; 65: 852-3.

17. Schwartzmann A, Peng P, Maciel MA, Forero M. Mechanism of the erector spinae plane block: insights from a magnetic resonance imaging study. Can J Anaesth 2018; 65: 1165-6.

18. Alici HA, Ahiskalioglu A, Aydin ME, Ahiskalioglu EO, Celik M. High volume single injection lumbar erector spinae plane block provides effective analgesia for lower extremity herpes zoster. J Clin Anesth 2019; 54: 136-7.

19. Chung K, Kim ED. Continuous erector spinae plane block at the lower lumbar level in a lower extremity complex regional pain syndrome patient. J Clin Anesth 2018; 48: 30-1.

20. Ueshima H, Otake H. Blocking of multiple posterior branches of cervical nerves using an erector spinae plane block. J Clin Anesth 2018; 46: 44.

21. Ueshima H, Hiroshi O. Erector spinae plane block for carotid endarterectomy. J Clin Anesth 2018; 48: 11.

22. Ueshima H, Otake H. Continuous erector spinae plane block for pain management of an extensive burn. Am J Emerg Med 2018; 36: 2130.

23. Tekin E, Ahiskalioglu A, Aydin ME, Sengun E, Bayramoglu A, Alici HA. High-thoracic ultrasound-guided erector spinae plane block for acute herpes zoster pain management in emergency department. Am J Emerg Med 2019; 37: 375.

24. Tsui BCH, Mohler D, Caruso TJ, Horn JL. Cervical erector spinae plane block catheter using a thoracic approach: an alternative to brachial plexus blockade for forequarter amputation. Can J Anaesth 2019; 66: 119-20.

25. Kumar A, Hulsey A, Martinez-Wilson H, Kim J, Gadsden J. The use of liposomal bupivacaine in erector spinae plane block to minimize opioid consumption for breast surgery: a case report. A A Pract 2018; 10: 239-41.

26. Ueshima H, Otake H. Limitations of the Erector Spinae Plane (ESP) block for radical mastectomy. J Clin Anesth 2018; $51: 97$.

27. Ueshima H, Otake H. A combination of an erector spinae plane block and a transversus thoracic muscle plane block for partial mastectomy. J Clin Anesth 2019; 54: 1.

28. Veiga M, Costa D, Brazão I. Erector spinae plane block for radical mastectomy: a new indication? Rev Esp Anestesiol Reanim 2018; 65: $112-$ 5.

29. Jones MR, Urits I, Shnider MR, Matyal R. Confirmation of erector spinae plane block analgesia for 3 distinct scenarios: a case report. A A Pract 2019; 12: 141-4.

30. De Cassai A, Marchet A, Ori C. The combination of erector spinae plane block and pectoralis blocks could avoid general anesthesia for radical mastectomy in high risk patients. Minerva Anestesiol 2018; 84: 1420-1.

31. Kimachi PP, Martins EG, Peng P, Forero M. The erector spinae plane block provides complete surgical anesthesiain breast surgery: a case report. A A Pract 2018; 11: 186-8.

32. Balaban O, Aydin T, Yaman M. Is ultrasound guided erector spinae plane block sufficient for surgical anesthesia in minor surgery at thoracal region? J Clin Anesth 2018; 47: 7-8.

33. Bonvicini D, Tagliapietra L, Giacomazzi A, Pizzirani E. Bilateral ultrasound-guided erector spinae plane blocks in breast cancer and 
reconstruction surgery. J Clin Anesth 2018; 44: 3-4.

34. Ohgoshi Y, Ikeda T, Kurahashi K. Continuous erector spinae plane block provides effective perioperative analgesia for breast reconstruction using tissue expanders: a report of two cases. J Clin Anesth 2018; 44: 1-2.

35. Singh S, Chowdhary NK. Erector spinae plane block an effective block for post-operative analgesia in modified radical mastectomy. Indian J Anaesth 2018; 62: 148-50.

36. Bonvicini D, Giacomazzi A, Pizzirani E. Use of the ultrasound-guided erector spinae plane block in breast surgery. Minerva Anestesiol 2017; 83: 1111-2.

37. Finneran JJ 4th, Gabriel RA, Khatibi B. Erector spinae plane blocks provide analgesia for breast and axillarysurgery: a series of 3 cases. Reg Anesth Pain Med 2018; 43: 101-2.

38. Ueshima H. Pneumothorax after the erector spinae plane block. J Clin Anesth 2018; 48: 12.

39. Wilson JM, Lohser J, Klaibert B. Erector spinae plane block for postoperative rescue analgesia in thoracoscopic surgery. J Cardiothorac Vasc Anesth 2018; 32: e5-7.

40. Hu B, Zhou H, Zou X. The erector spinae plane block (ESPB) for non-intubated video-assisted thoracoscopic surgery. J Clin Anesth 2019; 54: 50-1.

41. Luis-Navarro JC, Seda-Guzmán M, Luis-Moreno C, López-Romero JL. The erector spinae plane block in 4 cases of video-assisted thoracic surgery. Rev Esp Anestesiol Reanim 2018; 65: 204-8.

42. Ince I, Ozmen O, Aksoy M, Zeren S, Ulas AB, Aydin Y. Erector spinae plane block catheter insertion under ultrasound guidance for thoracic surgery: case series of three patients. Eurasian J Med 2018; 50: 204-6.

43. Scimia P, Basso Ricci E, Droghetti A, Fusco P. The ultrasound-guided continuous erector spinae plane block for postoperative analgesia in video-assisted thoracoscopic lobectomy. Reg Anesth Pain Med 2017; 42: 537.

44. Taketa Y, Irisawa Y, Fujitani T. Ultrasound-guided erector spinae plane block elicits sensory loss around the lateral, but not the parasternal, portion of the thorax. J Clin Anesth 2018; 47: 84-5.

45. Adhikary SD, Pruett A, Forero M, Thiruvenkatarajan V. Erector spinae plane block as an alternative to epidural analgesia for post-operative analgesia following video-assisted thoracoscopic surgery: a case study and a literature review on the spread of local anaesthetic in the erector spinae plane. Indian J Anaesth 2018; 62: 75-8.

46. Hamilton DL, Manickam B. Erector spinae plane block for pain relief in rib fractures. Br J Anaesth 2017; 118: 474-5.

47. Luftig J, Mantuani D, Herring AA, Dixon B, Clattenburg E, Nagdev A. Successful emergency pain control for posterior rib fractures with ultrasound-guided erector spinae plane block. Am J Emerg Med 2018; 36: 1391-6.

48. Nandhakumar A, Nair A, Bharath VK, Kalingarayar S, Ramaswamy BP, Dhatchinamoorthi D. Erector spinae plane block may aid weaning from mechanical ventilation in patients with multiple rib fractures: case report of two cases. Indian J Anaesth 2018; 62: 139-41.

49. Raft J, Chin KJ, Belanger ME, Clairoux A, Richebé P, Brulotte V. Continuous Erector Spinae Plane Block for thoracotomy analgesia after epidural failure. J Clin Anesth 2019; 54: 132-3.

50. Ciftci B, Ekinci M, Demiraran Y. Ultrasound-guided single-shot preemptive erector spinae plane blockfor postoperative pain management. J Cardiothorac Vasc Anesth 2019; 33: 1175-6.

51. Forero M, Rajarathinam M, Adhikary S, Chin KJ. Continuous erector spinae plane block for rescue analgesia in thoracotomy after epidural failure: a case report. A A Case Rep 2017; 8: 254-6.

52. De Cassai A, Ieppariello G, Ori C. Erector spinae plane block and dual antiplatelet therapy. Minerva Anestesiol 2018; 84: 1230-1.

53. Adhikary SD, Prasad A, Soleimani B, Chin KJ. Continuous erector spinae plane block as an effective analgesic option in anticoagulated patients after left ventricular assist device implantation: a case series. J Cardiothorac Vasc Anesth 2019; 33: 1063-7.

54. Tanaka N, Ueshima H, Otake H. Erector spinae plane block for combined lovectomy and radical mastectomys. J Clin Anesth 2018; 45: 27-8.

55. Ueshima H, Otake H. Erector spinae plane block provides effective pain management during pneumothorax surgery. J Clin Anesth 2017; 40: 74 .

56. Ueshima H, Otake H. Clinical experiences of erector spinae plane block for children. J Clin Anesth 2018; 44: 41.

57. De la Cuadra-Fontaine JC, Concha M, Vuletin F, Arancibia H. Continuous Erector Spinae Plane block for thoracic surgery in a pediatric patient. Paediatr Anaesth 2018; 28: 74-5.

58. Wyatt K, Elattary T. The erector spinae plane block in a high-risk Ehlers-Danlos syndrome pediatric patient for vascular ring repair. J Clin Anesth 2019; 54: 39-40.

59. Gaio-Lima C, Costa CC, Moreira JB, Lemos TS, Trindade HL. Continuous erector spinae plane block for analgesia in pediatric thoracic surgery: a case report. Rev Esp Anestesiol Reanim 2018; 65: 287-90.

60. de Haan JB, Hernandez N, Sen S. Erector spinae block for postoperative analgesia following axillary hidradenitis suppurativa resection: a case report. Local Reg Anesth 2018; 11: 87-90.

61. Ahiskalioglu A, Yayik AM, Celik EC, Ahiskalioglu EO, Emsen M. Two plane two block for surgical anesthesia: ultrasound-guided serratus and Erector Spinae Plane Blocks. J Clin Anesth 2018; 47: 19-20.

62. Cesur S, Ay AN, Yayık AM, Naldan ME, Gürkan Y. Ultrasound-guided erector spinae plane block provides effective perioperative analgesia and anaesthesia for thoracic mass excision: a report of two cases. Anaesth Crit Care Pain Med 2019; 38: 189-90.

63. Hernandez MA, Palazzi L, Lapalma J, Forero M, Chin KJ. Erector spinae plane block for surgery of the posterior thoracic wall in a pediatric 
patient. Reg Anesth Pain Med 2018; 43: 217-9.

64. Nardiello MA, Herlitz M. Bilateral single shot erector spinae plane block for pectus excavatum and pectus carinatum surgery in 2 pediatric patients. Rev Esp Anestesiol Reanim 2018; 65: 530-3.

65. Muñoz F, Cubillos J, Bonilla AJ, Chin KJ. Erector spinae plane block for postoperative analgesia in pediatric oncological thoracic surgery. Can J Anaesth 2017; 64: 880-2.

66. Ueshima H, Hiroshi O. Transapical transcatheter aortic valve implantation performed with an erector spinae plane block. J Clin Anesth 2018; 46: 84 .

67. Leyva FM, Mendiola WE, Bonilla AJ, Cubillos J, Moreno DA, Chin KJ. Continuous erector spinae plane (ESP) block for postoperative analgesia after minimally invasive mitral valve surgery. J Cardiothorac Vasc Anesth 2018; 32: 2271-4.

68. Chin KJ, Lewis S. Opioid-free analgesia for posterior spinal fusion surgery using erector spinae plane (ESP) blocks in a multimodal anesthetic regimen. Spine (Phila Pa 1976) 2019; 44: E379-83.

69. Ueshima H, Otake H. Clinical experiences of ultrasound-guided erector spinae plane block for thoracic vertebra surgery. J Clin Anesth 2017; 38: 137.

70. Tulgar S, Selvi O, Kapakli MS. Erector spinae plane block for different laparoscopic abdominal surgeries: case series. Case Rep Anesthesiol 2018; 2018: 3947281.

71. Hannig KE, Jessen C, Soni UK, Børglum J, Bendtsen TF. Erector spinae plane block for elective laparoscopic cholecystectomyin the ambulatory surgical setting. Case Rep Anesthesiol 2018; 2018: 5492527.

72. Petsas D, Pogiatzi V, Galatidis T, Drogouti M, Sofianou I, Michail A, et al. Erector spinae plane block for postoperative analgesia in laparoscopic cholecystectomy: a case report. J Pain Res 2018; 11: 1983-90.

73. Aksu C, Gürkan Y. Ultrasound-guided bilateral erector spinae plane block could provide effective postoperative analgesia in laparoscopic cholecystectomy in paediatric patients. Anesth Crit Care Pain Med 2018; 38: 87-8.

74. Thomas DT, Tulgar S. Ultrasound-guided erector spinae plane block in a child undergoing laparoscopic cholecystectomy. Cureus 2018; 10: e2241.

75. Aksu C, Gürkan Y. Erector spinae plane block: a new indication with a new approach and a recommendation to reduce the risk of pneumothorax. J Clin Anesth 2019; 54: 130-1.

76. Luis-Navarro JC, Seda-Guzmán M, Luis-Moreno C, Chin KJ. Erector spinae plane block in abdominal surgery: case series. Indian J Anaesth 2018; 62: 549-54.

77. Temirov T, Ben-David B, Mustafin A, Viderman D. Erector spinae plane block in management of pain after kidney transplantation. Pain Med 2019; 20: 1053-4.

78. Yamak Altinpulluk E, García Simón D, Fajardo-Pérez M. Erector spinae plane block for analgesia after lower segment caesarean section: case report. Rev Esp Anestesiol Reanim 2018; 65: 284-6.

79. Selvi O, Tulgar S. Ultrasound guided erector spinae plane block as a cause of unintended motor block. Rev Esp Anestesiol Reanim 2018; 65: 589-92.

80. Aksu C, Gürkan Y. Ultrasound guided erector spinae block for postoperative analgesia in pediatric nephrectomy surgeries. J Clin Anesth 2018; 45: 35-6.

81. Hacibeyoglu G, Topal A, Arican S, Kilicaslan A, Tekin A, Uzun ST. USG guided bilateral erector spinae plane block is an effective and safe postoperative analgesia method for living donor liver transplantation. J Clin Anesth 2018; 49: 36-7.

82. Tulgar S, Senturk O. Ultrasound guided low thoracic erector spinae plane block for postoperative analgesia in radical retropubic prostatectomy, a new indication. J Clin Anesth 2018; 47: 4.

83. Restrepo-Garces CE, Chin KJ, Suarez P, Diaz A. Bilateral continuous erector spinae plane block contributes to effective postoperative analgesia after major open abdominal surgery: a case report. A A Case Rep 2017; 9: 319-21.

84. Munshey F, Rodriguez S, Diaz E, Tsui B. Continuous erector spinae plane block for an open pyeloplasty in an infant. J Clin Anesth 2018; 47: 47-9.

85. Elkoundi A, Chouikh C, Baite A, Bensghir M, Bakkali H, Lalaoui SJ. Successful erector spinae plane block without ultrasound guidance in a severely cardiovascular compromised patient. J Clin Anesth 2019; 53: 50.

86. Tulgar S, Thomas DT, Deveci U. Erector spinae plane block provides sufficient surgical anesthesia for ileostomy closure in a high-risk patient. J Clin Anesth 2018; 48: 2-3.

87. Chin KJ, Adhikary S, Sarwani N, Forero M. The analgesic efficacy of pre-operative bilateral erector spinae plane (ESP) blocks in patients having ventral hernia repair. Anaesthesia 2017; 72: 452-60.

88. Chung K, Kim ED. Erector spinae plane block at the lower thoracic level for postoperative pain management after spinal cord stimulation implantation. Pain Med 2018; 19: 2330-2.

89. Hernandez MA, Palazzi L, Lapalma J, Cravero J. Erector spinae plane block for inguinal hernia repair in preterm infants. Paediatr Anaesth 2018; 28: 298-9.

90. Aksu C, Gürkan Y. Opioid sparing effect of Erector Spinae Plane block for pediatric bilateral inguinal hernia surgeries. J Clin Anesth 2018; 50: $62-3$.

91. Aksu C, Gürkan Y. Aksu approach for lumbar erector spinae plane block for pediatric surgeries. J Clin Anesth 2019; 54: 74-5. 
92. Melvin JP, Schrot RJ, Chu GM, Chin KJ. Low thoracic erector spinae plane block for perioperative analgesia in lumbosacral spine surgery: a case series. Can J Anaesth 2018; 65: 1057-65.

93. Calandese F, Adduci A. Erector spinae plane block for acute postoperative pain management after anterior thoracolumbar spine surgery. J Clin Anesth 2019; 52: 55-6.

94. Elkoundi A, Eloukkal Z, Bensghir M, Belyamani L, Lalaoui SJ. Erector spinae plane block for hyperalgesic acute pancreatitis. Pain Med 2019; 20: 1055-6.

95. Ahiskalioglu A, Alici HA, Ari MA. Ultrasound guided low thoracic erector spinae plane block for management of acute herpes zoster. J Clin Anesth 2018; 45: 60-1.

96. Ahiskalioglu A, Kocak AO, Doymus O, Sengun E, Celik M, Alici HA. Erector spinae plane block for bilateral lumbar transverse process fracture in emergency department: a new indication. Am J Emerg Med 2018; 36: 1927.

97. Kim E, Kwon W, Oh S, Bang S. The erector spinae plane block for postoperative analgesia after percutaneous nephrolithotomy. Chin Med J (Engl) 2018; 131: 1877-8.

98. Tulgar S, Selvi O, Senturk O, Ermis MN, Cubuk R, Ozer Z. Clinical experiences of ultrasound-guided lumbar erector spinae plane block for hip joint and proximal femur surgeries. J Clin Anesth 2018; 47: 5-6.

99. Tulgar S, Ermis MN, Ozer Z. Combination of lumbar erector spinae plane block and transmuscular quadratus lumborum block for surgical anaesthesia in hemiarthroplasty for femoral neck fracture. Indian J Anaesth 2018; 62: 802-5.

100. Darling CE, Pun SY, Caruso TJ, Tsui BC. Successful directional thoracic erector spinae plane block after failed lumbar plexus block in hip joint and proximal femur surgery. J Clin Anesth 2018; 49: 1-2.

101. Bugada D, Zarcone AG, Manini M, Lorini LF. Continuous Erector Spinae Block at lumbar level (L4) for prolonged postoperative analgesia after hip surgery. J Clin Anesth 2019; 52: 24-5.

102. Tulgar S, Senturk O. Ultrasound guided Erector Spinae Plane block at L-4 transverse process level provides effective postoperative analgesia for total hip arthroplasty. J Clin Anesth 2018; 44: 68.

103. Goodman DA. Erector spinae block at L2 for thigh lift surgery, a new application. J Clin Anesth 2019; 52: 82.

104. Tulgar S, Kapakli MS, Senturk O, Selvi O, Serifsoy TE, Ozer Z. Evaluation of ultrasound-guided erector spinae plane block for postoperative analgesia in laparoscopic cholecystectomy: a prospective, randomized, controlled clinical trial. J Clin Anesth 2018; 49: 101-6.

105. Gürkan Y, Aksu C, Kuş A, Yörükoğlu UH, Kılıç CT. Ultrasound guided erector spinae plane block reduces postoperative opioid consumption following breast surgery: a randomized controlled study. J Clin Anesth 2018; 50: 65-8.

106. Oksuz G, Bilgen F, Arslan M, Duman Y, Urfalıglu A, Bilal B. Ultrasound-guided bilateral erector spinae block versus tumescent anesthesia for postoperative analgesia in patients undergoing reduction mammoplasty: a randomized controlled study. Aesthetic Plast Surg 2019; 43: 291-6.

107. Altıparmak B, Korkmaz Toker M, Uysal Aİ, Turan M, Gümüş Demirbilek S. Comparison of the effects of modified pectoral nerve block and erector spinae plane block on postoperative opioid consumption and pain scores of patients after radical mastectomy surgery: a prospective, randomized, controlled trial. J Clin Anesth 2019; 54: 61-5.

108. Nagaraja PS, Ragavendran S, Singh NG, Asai O, Bhavya G, Manjunath N, et al. Comparison of continuous thoracic epidural analgesia with bilateral erector spinae plane block for perioperative pain management in cardiac surgery. Ann Card Anaesth 2018; 21: 323-7.

109. Krishna SN, Chauhan S, Bhoi D, Kaushal B, Hasija S, Sangdup T, et al. Bilateral erector spinae plane block for acute post-surgical pain in adult cardiac surgical patients: a randomized controlled trial. J Cardiothorac Vasc Anesth 2019; 33: 368-75.

110. Macaire P, Ho N, Nguyen T, Nguyen B, Vu V, Quach C, et al. Ultrasound-guided continuous thoracic erector spinae plane block within an enhanced recovery program is associated with decreased opioid consumption and improved patient postoperative rehabilitation after open cardiac surgery-a patient-matched, controlled before-and-after study. J Cardiothorac Vasc Anesth 2019; 33: 1659-67.

111. Tulgar S, Selvi O, Ozer Z. Clinical experience of ultrasound-guided single and bi-level erector spinae plane block for postoperative analgesia in patients undergoing thoracotomy. J Clin Anesth 2018; 50: 22-3.

112. Ueshima H, Inagaki M, Toyone T, Otake H. Efficacy of the erector spinae plane block for lumbar spinal surgery: a retrospective study. Asian Spine J 2019; 13: 254-7.

113. Tsui BC, Fonseca A, Munshey F, McFadyen G, Caruso TJ. The erector spinae plane (ESP) block: a pooled review of 242 cases. J Clin Anesth 2019; 53: 29-34.

114. El-Boghdadly K, Pawa A. The erector spinae plane block: plane and simple. Anaesthesia 2017; 72: 434-8.

115. De la Cuadra-Fontaine JC, Altermatt FR. Continuous Erector Spinae Plane (ESP) block: optimizing the analgesia technique. J Cardiothorac Vasc Anesth 2018; 32: e2-3.

116. Noss C, Anderson KJ, Gregory AJ. Erector spinae plane block for open-heart surgery: a potential tool for improved analgesia. J Cardiothorac Vasc Anesth 2019; 33: 376-7.

117. Ueshima H, Otake H. Similarities between the retrolaminar and erector spinae plane blocks. Reg Anesth Pain Med 2017; 42: 123-4.

118. Murouchi T. Consideration of block nomenclature: erector spinae plane block or retrolaminar block? Reg Anesth Pain Med $2017 ; 42: 124$.

119. Hamilton DL, Manickam B. The erector spinae plane block. Reg Anesth Pain Med 2017; $42: 276$.

120. Cornish PB. Erector spinae plane block: the "happily accidental" paravertebral block. Reg Anesth Pain Med 2018; 43: 644-5.

121. Chin KJ, Forero M, Adhikary SD. Reply to Dr Ueshima and Dr Murouchi. Reg Anesth Pain Med 2017; 42: 124-5. 
122. Josh Luftig PA, Mantuani D, Herring AA, Dixon B, Clattenburg E, Nagdev A. The authors reply to the optimal dose and volume of local anesthetic for erector spinae plane blockade for posterior rib fractures. Am J Emerg Med 2018; 36: 1103-4.

123. Kose HC, Kose SG, Thomas DT. Lumbar versus thoracic erector spinae plane block: similar nomenclature, different mechanism of action. J Clin Anesth 2018; 48: 1.

124. Yang HM, Choi YJ, Kwon HJ, O J, Cho TH, Kim SH. Comparison of injectate spread and nerve involvement between retrolaminar and erector spinae plane blocks in the thoracic region: a cadaveric study. Anaesthesia 2018; 73: 1244-50.

125. Ivanusic J, Konishi Y, Barrington MJ. A cadaveric study investigating the mechanism of action of erector spinae blockade. Reg Anesth Pain Med 2018; 43: 567-71.

126. Chong MA, Berbenetz NM, Lin C, Singh S. Perineural versus intravenous dexamethasone as an adjuvant for peripheral nerve blocks: a systematic review and meta-analysis. Reg Anesth Pain Med 2017; 42: 319-26.

127. Elsharkawy H, Maniker R, Bolash R, Kalasbail P, Drake RL, Elkassabany N. Rhomboid intercostal and subserratus plane block: a cadaveric and clinical evaluation. Reg Anesth Pain Med 2018; 43: 745-51.

128. Aygun H, Thomas DT, Tulgar S. Reply to Goodman: Lumbar erector spinae plane block for thigh lift surgery: which level, which block and which procedure? J Clin Anesth 2019; 53: 75.

129. Bonvicini D, Tagliapietra L. Reply to DR. De Cassai et al. J Clin Anesth 2018; 49: 131.

130. Chaudhary NK, Singh S. The right plane for drug injection in ultrasound-guided erector spinae plane block. Indian J Anaesth $2018 ; 62: 405$.

131. Chin KJ, Adhikary S, Forero M. Is the erector spinae plane (ESP) block a sheath block? A reply. Anaesthesia 2017; 72: 916-7.

132. Costache I, de Neumann L, Ramnanan CJ, Goodwin SL, Pawa A, Abdallah FW, et al. The mid-point transverse process to pleura (MTP) block: a new end-point for thoracic paravertebral block. Anaesthesia 2017; 72: 1230-6.

133. De Cassai A, Stefani G, Ori C. Erector spinae plane block and brachial plexus. J Clin Anesth 2018; 45: 32.

134. Greenhalgh K, Womack J, Marcangelo S. Injectate spread in erector spinae plane block. Anaesthesia 2019; 74: 126-7.

135. Hamilton DL, Manickam BP. Is the erector spinae plane (ESP) block a sheath block? Anaesthesia 2017; 72: 915-6.

136. Hamilton DL. Pneumothorax following erector spinae plane block. J Clin Anesth 2019; 52: 17.

137. Kashani HH, Grocott HP. Clarity needed as to the optimal dose and volume of local anesthetic for erector spinae plane blockade for posterior rib fractures. Am J Emerg Med 2018; 36: 1102-3.

138. Tulgar S, Balaban O. Local anaesthetic injection point of erector spinae plane block. Indian J Anaesth 2018; 62: 403-4.

139. Tulgar S, Ahiskalioglu A, Balaban O. Reply to Dr. Ueshima: The relationship of local anesthetic volume and dermatomal spread of sensorial block in erector spinae plane blocks: a new dilemma. J Clin Anesth 2019; 52: 57. 